\title{
Silicate-substituted calcium phosphate as a bone void filler after kyphoplasty in a young patient with multiple compression fractures due to osteogenesis imperfecta variant
}

\author{
Case report
}

\author{
MitChell A. HaRdenbrooK, M.D., L.C.D.R., M.C., U.S.N., AND \\ SERGio R. Lombardo, D.O., L.T., M.C., U.S.N. \\ Department of Orthopaedic Surgery, Uniformed Services University of the Health Sciences, \\ Naval Medical Center, Portsmouth, Virginia
}

\begin{abstract}
$\checkmark$ Kyphoplasty can be used to treat compression fractures resulting from a variety of causes. The use of polymethyl methacrylate (PMMA) in conjunction with kyphoplasty has many risks and potential complications, however, particularly in the younger patient population. Silicate-substituted calcium phosphate (Actifuse Synthetic Bone Graft; Apatech, Ltd.) is an alternative to PMMA that provides immediate pain relief and the ability to heal and incorporate within the vertebral body.
\end{abstract}

\section{KEY WORDS • compression fracture • osteogenesis imperfecta • kyphoplasty • bone graft}

$\mathrm{K}$ YPHOPLASTY with PMMA is an accepted treatment for osteoporotic compression fractures of the thoracic and lumbar spine that are resistant to conservative treatment. ${ }^{7,11,12,16,19,23}$ Indications for kyphoplasty have expanded to include compression fractures associated with hemangiomas, ${ }^{1}$ myeloma, ${ }^{3}$ and other neoplastic processes. ${ }^{4,6,8}$ There is concern, however, about the intraoperative, perioperative, and postoperative complications associated with PMMA. 5,7,9,12,14,24 As a result, alternative bone-filling materials have been investigated to minimize the potential complications associated with PMMA. ${ }^{13}$ In this case study we present a young patient with multiple compression fractures associated with a rare metabolic disorder that were treated with kyphoplasty in which a silicate-substituted calcium phosphate bone filler (Actifuse Synthetic Bone Graft; Apatech, Ltd.) was used.

\section{Case Report}

History and Examination. This 25-year-old man presented with a 13-month history of low-back pain radiating to the right lower extremity, accompanied by numbness and paresthesias. He rated his back pain as a 5 on a scale of 0 to 10 in intensity, worsening to an 8 with minimal activities. On physical examination, the patient had tenderness

\footnotetext{
Abbreviations used in this paper: $\mathrm{AP}=$ anteroposterior; $\mathrm{CT}=$ computed tomography; PMMA = polymethyl methacrylate; $\mathrm{VB}=$ vertebral body.
}

to palpation of the lower lumbar spine and asymmetrical weakness of the right quadriceps. Initial AP and lateral radiographs of the lumbar spine (Fig. 1) showed compression fractures of nearly all VBs, with a radiographic appearance of osteoporosis. Magnetic resonance imaging of the lumbar spine (Fig. 2) revealed multiple compression fractures and foraminal stenosis in the right L3-4 and L4-5. Dual-energy x-ray absorptiometry of the lumbar spine showed a bone mineral density of 0.62 and a T-score of -4.28 , which is consistent with severe osteoporosis. After an extensive metabolic evaluation, a rare variant of osteogenesis imperfecta was diagnosed. The patient's pain failed to improve despite bracing, medication, and activity modification that continued for 9 months. He therefore underwent kyphoplasty of L-3, L-4, and L-5 in which silicate-substituted calcium phosphate was used as a bone void filler, and foraminotomy of the right L3-4 and L4-5 was also performed.

Operation. A void was created in each vertebra by using a balloon tamp (Kyphon), and silicate-substituted calcium phosphate crystals were inserted through a 4-mm cannula into the L-3, L-4, and L- 5 VBs. The amount of bone filler inserted was determined by the volume of the void created by the balloon tamp. Kyphoplasty at L-3 and L-4 was performed via a unipedicular approach, whereas the L-5 kyphoplasty was performed via a bipedicular approach. The bone void filler was easily visualized using fluoroscopic imaging intraoperatively (Fig. 3). The right L-3 and L-4 nerve roots were decompressed without incident. The 


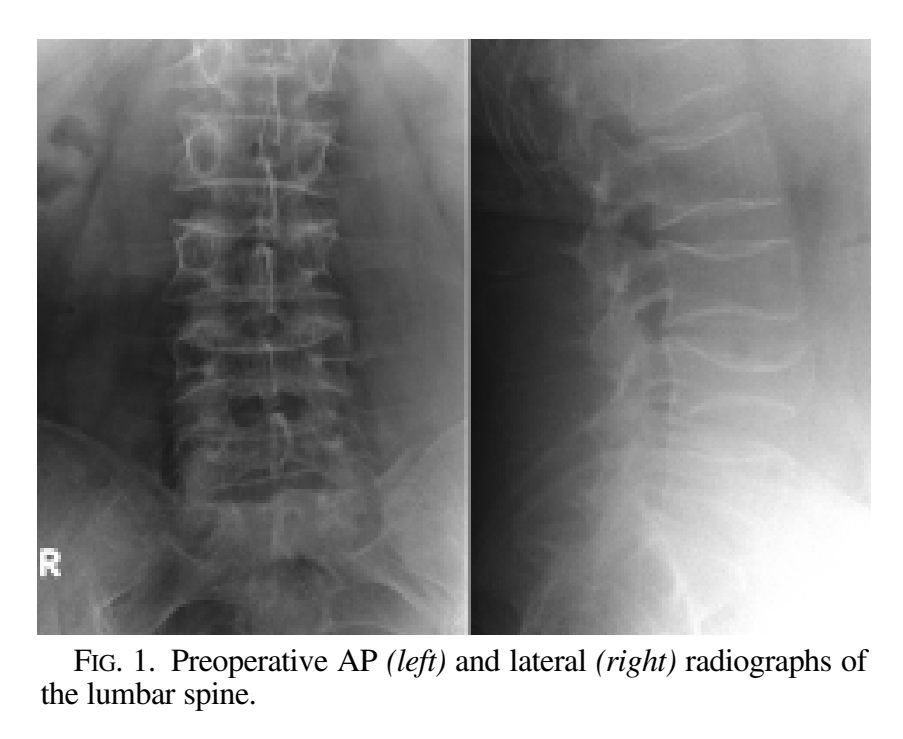

patient tolerated the procedure well without complications.

Postoperative Course. On postoperative Day 1, before the patient was discharged, standing AP and lateral radiographs of the lumbar spine were obtained (Fig. 4), which showed the bone void filler within the VBs. At his initial follow-up appointment 4 weeks postoperatively, the patient described improvement of his back pain and mild improvement of his right leg symptoms. Follow-up radiographs of the lumbar spine (Fig. 5) were obtained at 3 and 5 months postoperatively, and these showed bone incorporation. Axial (Fig. 6A and B) and sagittal (Fig. 6C) CT scans of the lumbar spine obtained 9 months postoperatively demonstrated trabecular bone forming into the bone filler and no lucency around the bone filler, confirming bone incorporation of the silicate-substituted calcium phosphate crystals within the VBs. Clinically, the patient had minimal back pain at the most recent follow-up visit 9 months postoperatively.

\section{Discussion}

There were few good treatment options for this relatively young patient who presented with debilitating back pain due to multiple compression fractures and severe osteoporosis. Posterior lumbar fusion was a poor option for this patient, given his inferior quality of bone and his young age. Kyphoplasty was a viable option for treating the compression fractures, but there is debate about the appropriate bone void filler.

Traditionally, PMMA is used in kyphoplasty to provide immediate structural support from within the VB. The benefits of PMMA are that it hardens quickly after insertion, is relatively inexpensive, and is easy to inject. However, PMMA has many potential drawbacks. There is concern for extravasation of PMMA outside the confines of the VB, with potential injury to nerves and vascular structures. ${ }^{7,12}$ The release of methyl methacrylate monomer into the vascular system during injection can result in acute hypotension, and there have been reports of cardiovascular collapse. ${ }^{14}$ Also, PMMA cannot be incorporated biologically into the VB and remains, in essence, a foreign substance within the VB. There is also concern that the difference in modulus of elasticity of PMMA compared

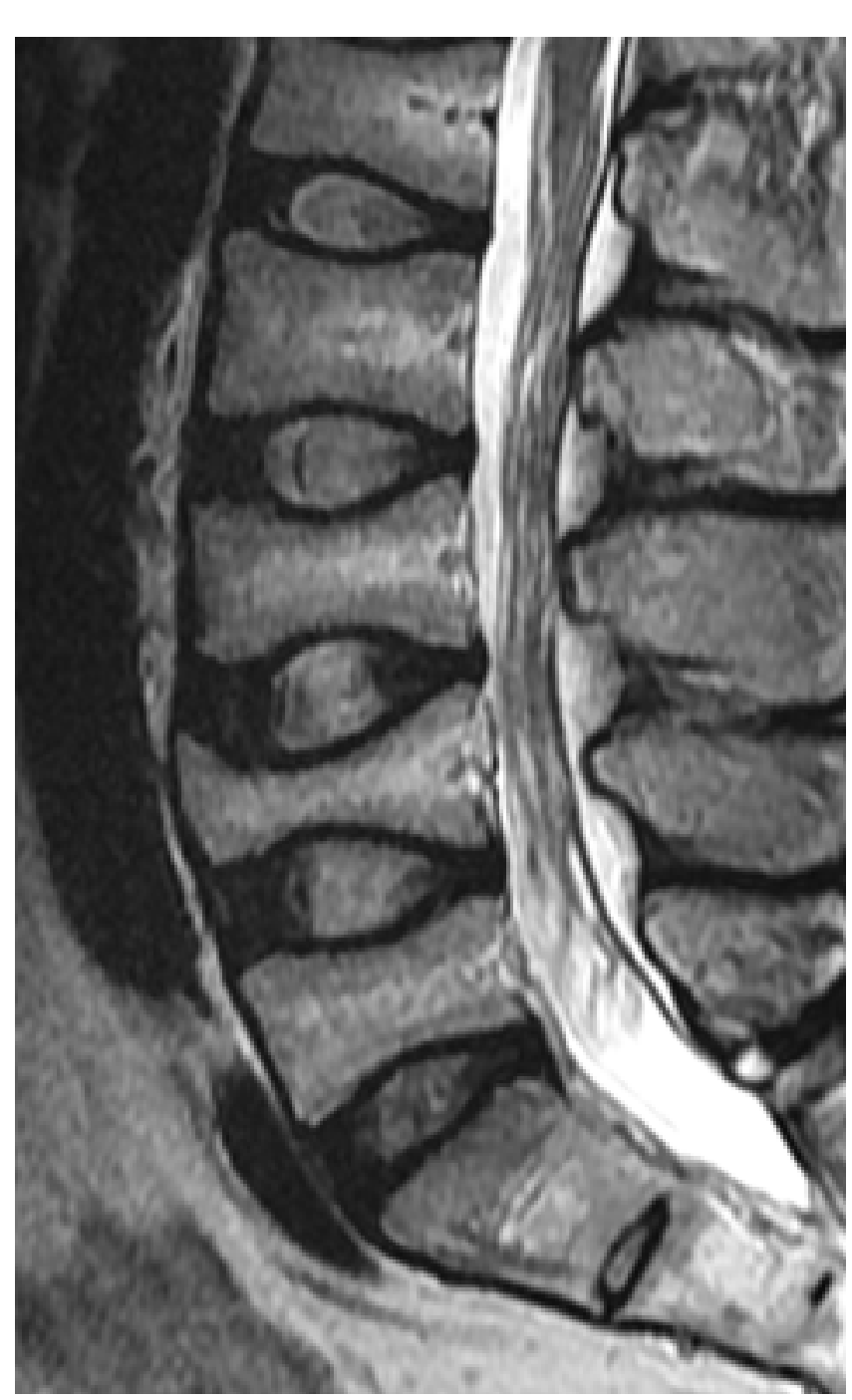

FIG. 2. Preoperative sagittal magnetic resonance image of the lumbar spine.

with native and osteoporotic bone could result in additional compression fractures at adjacent vertebrae. ${ }^{5}$ These potential side effects of PMMA are a concern in all patients, but they are particularly salient in this young one.

Although there is a case report describing the use of PMMA augmentation in treating a single-level compression fracture due to osteogenesis imperfecta, ${ }^{18}$ that patient was 57 years old. Our patient, on the other hand, was 25 years old and had multiple levels requiring treatment. We believed that a better choice would be a more biological bone void filler with the potential to form new bone and incorporate into the VB.

There are reports of alternative materials considered for use in patients undergoing kyphoplasty or vertebroplasty, including calcium phosphate and calcium sulfate. ${ }^{13}$ Although calcium phosphate can provide structural support and osteoconduction, there are concerns about its ability to produce healing in metabolically diseased bone. Combining bone morphogenetic protein-2 with the calcium phosphate ${ }^{22}$ could improve its osteoinductive properties, but this substance is very expensive. Calcium sulfate 


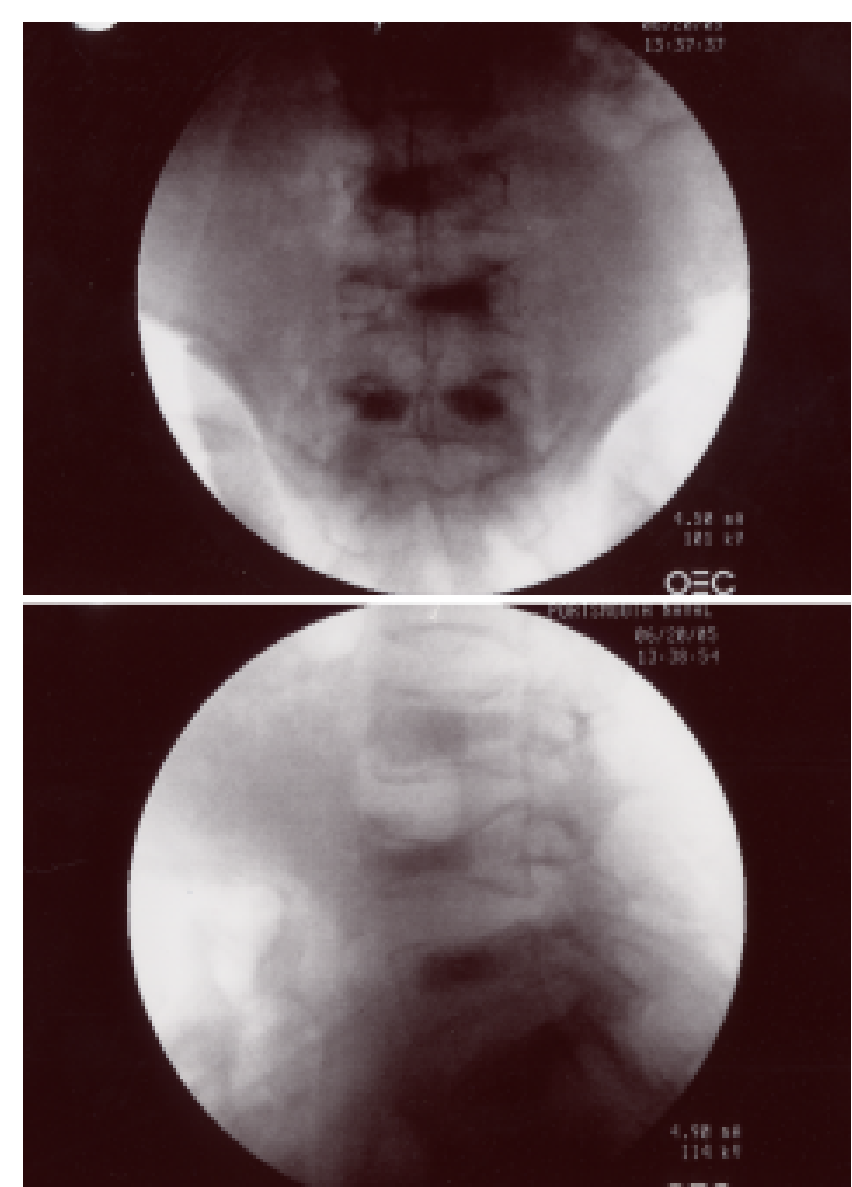

FIG. 3. Intraoperative fluoroscopic images of L-3, L-4, and L-5 kyphoplasty.

can provide an osteoconductive scaffold, but it tends to be rapidly resorbed, limiting its usefulness in vertebral augmentation. ${ }^{25}$

Silicate-substituted calcium phosphate has unique characteristics that make it the most appropriate selection. Silicate-substituted calcium phosphate is a phase-pure $80 \%$ porous calcium phosphate material in which the phos-

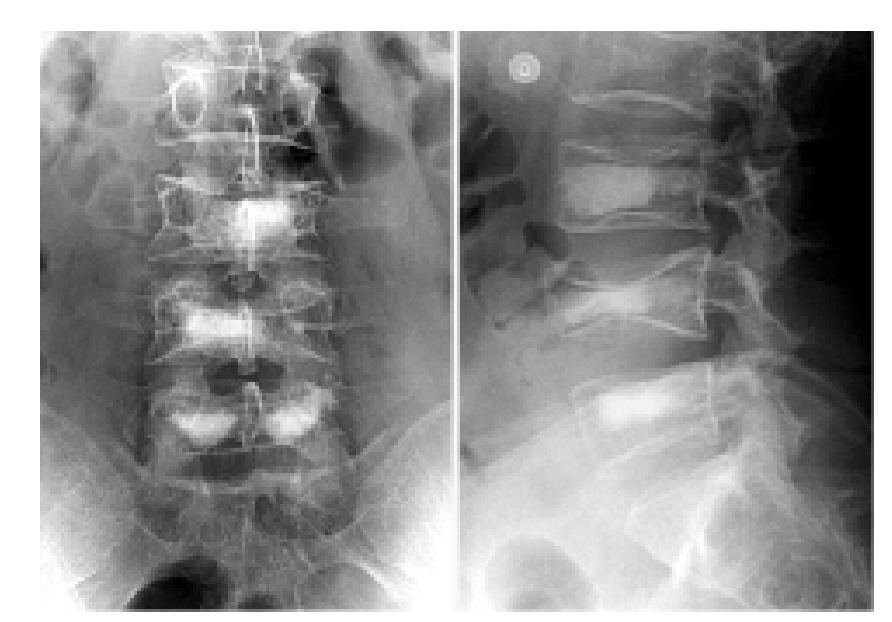

FIG. 4. Standing AP (left) and lateral (right) radiographs of the lumbar spine obtained on postoperative Day 1. phate groups are selectively replaced with silicate ions. Whereas the calcium phosphate scaffolding has the structural support and osteoconduction of traditional calcium phosphate bone filler, the addition of silicate ions increases its osteoinductive properties. Studies have shown that silicon, in vivo, enhances osteoblastic differentiation and stimulates the formation of bone. ${ }^{15,17}$ Moreover, in some reports it has been suggested that silicon is a significant dietary trace element for bone formation and remodeling. 2,10,20,21

These osteoinductive properties combined with the osteoconductive microstructure of the calcium phosphate lattice provide a rich environment for rapid bone incorporation. This was radiographically evident in our patient on the postoperative $\mathrm{x}$-ray films and CT scan obtained 9 months postoperatively, which showed incorporation of bone within the VB. Additionally, the granules of silicatesubstituted calcium phosphate provided structural support of the compressed vertebrae. This was clinically evident in the improvement of the patient's back pain at the initial postoperative visit at 4 weeks.

The use of silicate-substituted calcium phosphate after kyphoplasty allowed this patient with compression fractures to gain enough structural support to provide early

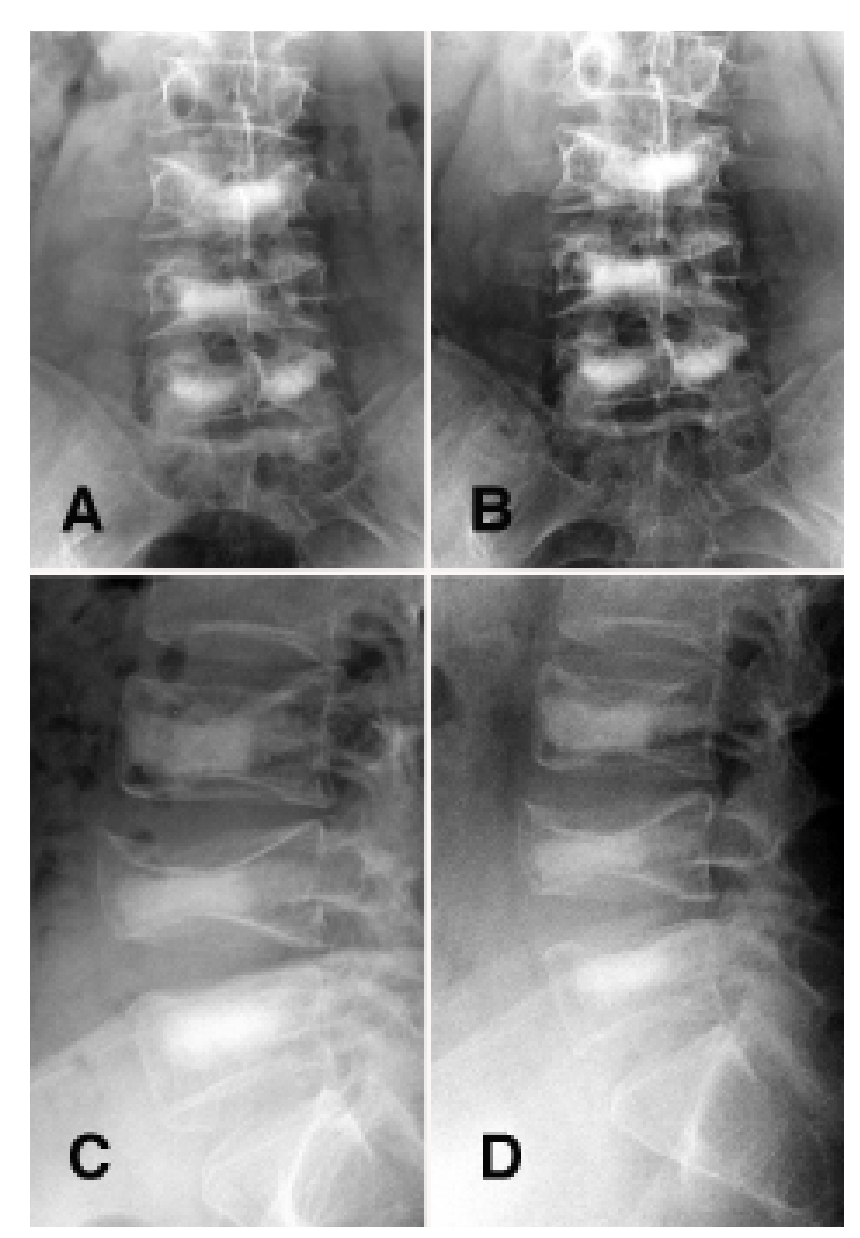

FIG. 5. Follow-up AP radiographs of the lumbar spine obtained 3 (A) and 5 months (B) postoperatively. Follow-up lateral radiographs of the lumbar spine obtained 3 (C) and 5 months (D) postoperatively. 


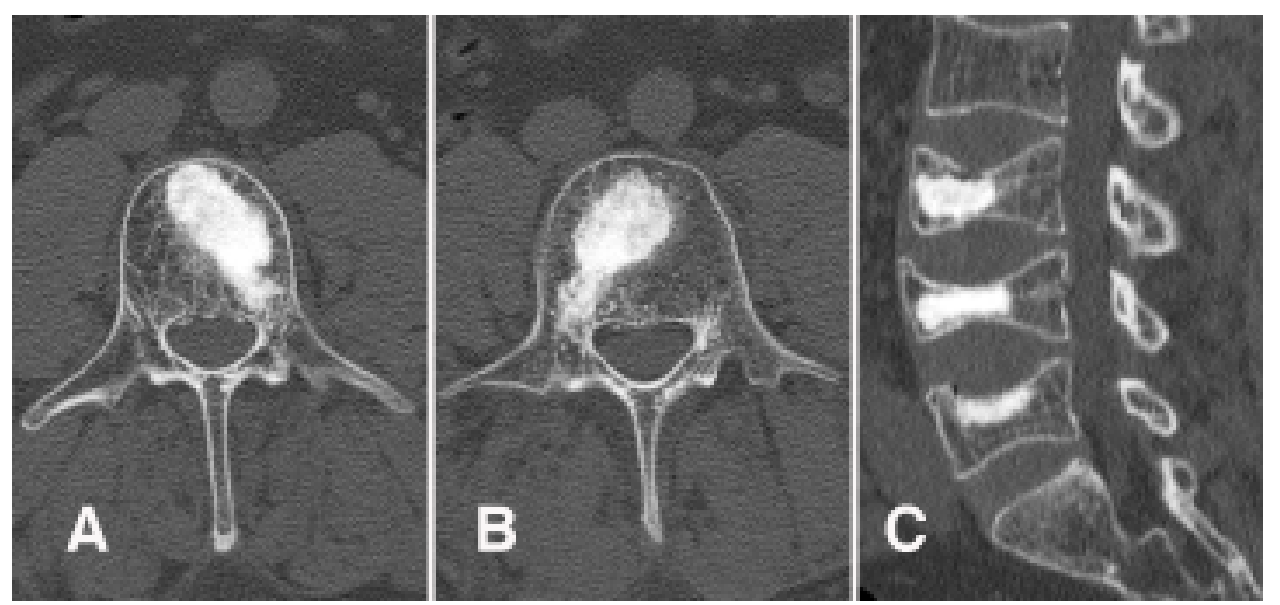

FIG. 6. A and B: Axial CT scans of L-3 and L-4 obtained 9 months postoperatively. C: Sagittal CT scan of the lumbar spine obtained 9 months postoperatively.

relief of back pain while providing a substrate for incorporation and healing within the bone of the VB. Through this approach, we were able to treat multiple compression fractures successfully in a young adult with severe osteoporosis and avoid using PMMA, with all of its potential short- and long-term complications.

\section{Conclusions}

Silicate-substituted calcium phosphate is an ideal substance to use in conjunction with kyphoplasty for the treatment of compression fractures. In this case report we show that Actifuse gives immediate structural support sufficient to decrease pain from compression fractures in the postoperative period and facilitates bone incorporation due to the osteoinductive properties of the silicate ions, even in metabolically diseased bone. Actifuse is radiopaque and easily visualized using fluoroscopic and radiographic imaging.

\section{References}

1. Atalay B, Caner H, Yilmaz C, Altinors N: Sacral kyphoplasty for relieving pain caused by sacral hemangioma. Spinal Cord 44:196-199, 2006

2. Carlisle EM: In vivo requirement for silicon in articular cartilage and connective tissue formation in the chick. J Nutr 106: $478-484,1976$

3. Dudeney S, Lieberman IH, Reinhardt MK, Hussein M: Kyphoplasty in the treatment of osteolytic vertebral compression fractures as a result of multiple myeloma. J Clin Oncol 20:2382-2387, 2002

4. Fourney DR, Schomer DF, Nader R, Chlan-Fourney J, Suki D, Ahrar K: Percutaneous vertebroplasty and kyphoplasty for oainful vertebral body fractures in cancer patients. J Neurosurg 98 (1 Suppl):21-30, 2003

5. Fribourg D, Tang C, Sra P, Delamarter R, Bae H: Incidence of subsequent vertebral fracture after kyphoplasty. Spine 29:2270-2276, 2004

6. Gaitanis IN, Hadjipavlou AG, Katonis PG, Tzermiadianos MN, Pasku DS, Patwardhan AG: Balloon kyphoplasty for the treatment of pathological vertebral compressive fractures. Eur Spine J 14:250-260, 2005

7. Garfin SR, Yuan HA, Reiley MA: New technologies in spine: kyphoplasty and vertebroplasty for the treatment of painful osteoporotic compression fractures. Spine 26:1511-1515, 2001

8. Hadjipavlou AG, Tzermiadianos MN, Katonis PG, Szpalski M: Percutaneous vertebroplasty and balloon kyphoplasty for the treatment of osteoporotic vertebral compression fractures and osteolytic tumors. J Bone Joint Surg Br 87:1595-1604, 2005

9. Jang JS, Lee, SH, Jung SK: Pulmonary embolism of polymethylmethacrylate after percutaneous vertebroplasty: a report of three cases. Spine 27: E416-E418, 2002

10. Jugdaohsingh R, Tucker KL, Qiao N, Cupples LA, Kiel DP, Powell JJ: Dietary silicon intake is positively associated with bone mineral density in men and premenopausal women of the Framingham Offspring Cohort. J Bone Miner Res 19: 297-307, 2004

11. Ledlie JT, Renfro M: Balloon kyphoplasty: one-year outcomes in vertebral body height restoration, chronic pain and activity levels. J Neurosurg 98:36-42, 2003

12. Lieberman IH, Dudeney S, Reinhardt MK, Bell G: Initial outcome and efficacy of "kyphoplasty" in the treatment of painful osteoporotic vertebral compression fractures. Spine 26: 1631-1638, 2001

13. Lieberman IH, Togawa D, Kayanja MM: Vertebroplasty and kyphoplasty: filler materials. Spine J 5:305S-316S, 2005

14. Nussbaum DA, Gailloud P, Murphy K: A review of complications associated with vertebroplasty and kyphoplasty as reported to the Food and Drug Administration medical device related web site. J Vasc Interv Radiol 15:1185-1196, 2004

15. Patel N, Brooks RA, Clarke MT, Lee PM, Rushton N, Gibson IR, et al: In vivo assessment of hydroxyapatite and silicate-substituted hydroxyapatite granules using ovine defect model. J Mater Sci Mater Med 16:429-440, 2005

16. Phillips FM, Ho E, Campbell-Hupp M, McNally T, Etzel FT, Gupta P: Early radiographic and clinical results of balloon kyphoplasty for the treatment of osteoporotic vertebral compression fractures. Spine 28:2260-2267, 2003

17. Porter AE, Patel N, Skepper JN, Best SM, Bonfield W: Effect of sintered silicate-substituted hydroxyapatite on remodeling processes at the bone-implant interface. Biomaterials 25: 3303-3314, 2004

18. Rami PM, McGraw JK, Heatwole EV, Boorstein JM: Percutaneous vertebroplasty in the treatment of vertebral body compression fracture secondary to osteogenesis imperfecta. Skeletal Radiol 31:162-165, 2002

19. Rao RD, Singrakhia MD: Painful osteoporotic vertebral fracture. Pathogenesis, evaluation and roles of vertebroplasty and kyphoplasty in its management. J Bone Joint Surg Am 85:2010-2022, 2003

20. Reffitt DM, Ogston N, Jugdaohsingh R, Cheung HF, Evans BA, 


\section{Synthetic bone graft as a bone void filler after kyphoplasty}

Thompson RP, et al: Orthosilicic acid stimulates collagen type 1 synthesis and osteoblastic differentiation in human osteoblast-like cells in vitro. Bone 32:127-135, 2003

21. Seaborn CD: Silicon deprivation decreases collagen formation in wounds and bones, and ornithine transaminase enzyme activity in liver. Biol Trace Elem Res:251-261, 2002

22. Seeherman HJ, Bouxsein M, Kim H, Li R, Jian Li X, Aiolova $\mathrm{M}$, et al: Recombinant human bone morphogenetic protein-2 delivered in an injectable calcium phosphate paste accelerates osteotomy-site healing in a nonhuman primate model. J Bone Joint Surg Am 86:1961-1972, 2004

23. Theodorou DJ, Theodorou SJ, Duncan TD, Garfin SR, Wong WH: Percutaneous balloon kyphoplasty for the correction of spinal deformity in painful vertebral body compression fractures. J Clin Imaging 26: 1-5, 2002

24. Togawa D, Bauer TW, Lieberman IH, Takikawa S: Histologic evaluation of human vertebral bodies after vertebral augmentation with polymethyl methacrylate. Spine 28:1521-1527, 2003

25. Walsh WR, Morberg P, Yu Y, Yang JL, Haggard W, Sheath PC, et al: Response of a calcium sulfate bone graft substitute in a confined cancellous defect. Clin Orthop Relat Res 406: 228-236, 2003

Manuscript received June 30, 2006.

Accepted in final form October 30, 2006.

Address reprint requests to: Mitchell A. Hardenbrook, M.D., L.C.D.R., M.C., U.S.N., Department of Orthopaedic Surgery, Uniformed Services University of the Health Sciences, Naval Medical Center, 620 John Paul Jones Circle, Portsmouth, Virginia 23708-2197. email: mahardenbrook@mar.med.navy.mil. 